\title{
Measuring Ionic Conductivity in Mixed Electron-ionic Conductors Based on the Ion-blocking Method
}

\author{
LIU Yong-Ying ${ }^{1,2}$, QIU Peng-Fei ${ }^{1}$, CHEN Hong-Yi ${ }^{1,2}$, CHEN Rui $^{1,2}$, SHI Xun ${ }^{1}$, CHEN Li-Dong ${ }^{1}$
}

(1. State Key Laboratory of High Performance Ceramics and Superfine Microstructure, Shanghai Institute of Ceramics, Chinese Academy of Sciences, Shanghai 200050, China; 2. University of Chinese Academy of Sciences, Beijing 100864, China)

\begin{abstract}
Ionic conductivity is common in liquid-like thermoelectric (TE) materials and it helps to understand the abnormal electrical and thermal transports. However, in experiment, accurately measuring the ionic conductivities in liquid-like TE materials is very difficult because of the very small contribution from ions to the total conductivity. In this study, based on the ion-blocking method proposed by Yokota, a home-made instrument has been built to accurately measure the ionic conductivity of liquid-like TE materials. The basic construction of this instrument and the measurement principles are introduced. The related factors that might influence the measurement accuracy are also analysed. Finally, the ionic conductivities for two typical liquid-like TE materials are presented to show the validity of our home-made instrument.
\end{abstract}

Key words: thermoelectric; ionic conductivity; ion-blocking method; ionic activation energy

Thermoelectric (TE) technology can directly convert waste heat into useful electricity, which may provide an alternative method to solve the global energy crisis $^{[1-5]}$. Recently, the liquid-like materials satisfying the "phononliquid electron-crystal" (PLEC) concept have attracted great attentions in TE community ${ }^{[6]}$. There are usually two different sub-lattices in the crystal structures of these liquid-like materials. One is the rigid anion sub-lattice and the other one is the "liquid-like" cation sub-lattice. Since there are many atomic positions with similar energies for the cations inside the anion sub- lattice, the cations can easily migrate from one position to another position like liquids. Many liquid-like materials, such as $\mathrm{Cu}_{2-\delta} \mathrm{X}(\mathrm{X}=\mathrm{S}, \mathrm{Se}, \mathrm{Te})^{[6-9]}, \mathrm{CuAgSe}^{[10-11]}, \mathrm{Cu}_{5} \mathrm{FeS}_{4}{ }^{[12]}$, $\mathrm{CuCrSe}_{2}{ }^{[13]}, \mathrm{Zn}_{4} \mathrm{Sb}_{3}{ }^{[14]}, \mathrm{Cu}_{7} \mathrm{PSe}_{6}{ }^{[15]}$ and $\mathrm{Cu}_{8} \mathrm{GeSe}_{6}{ }^{[16]}$ have demonstrated excellent TE performances which are comparable with the state-of-the-art TE materials reported before ${ }^{[17-19]}$.

However, the long range ion migration in liquid-like TE materials may affect material's chemical stability in real applications ${ }^{[20-22]}$. Under the external electric field, the movable ions can migrate from their initial high potential positions to the low potential area with high diffusivities, leading to the inhomogeneous ion concentration distribution along the sample and even the formation of metallic precipitates on the sample's surface. Generally, such kind of ion migration behavior can be quantitatively reflected by the ionic conductivity $\left(\sigma_{i}\right)^{[23]}$. Larger $\sigma_{i}$ indicates that there are more movable ions taking part in the migration, or the movable ions possessing high mobility. Nevertheless, in experiment, accurately measuring the $\sigma_{i}$ values of these liquid-like TE materials is very difficult because most of them are mixed electron-ionic conductors, in which the ions only contribute a little to the total conductivity $(\sigma)$. In this case, the common methods (e.g. electrochemical impedance spectroscopy) ${ }^{[24-25]}$ that are used to measure the $\sigma_{i}$ values in unipolar ionic-conductors are not suitable for these liquid- like TE materials. Addressing this issue, Yokota ${ }^{[26-27]}$ proposed an electron-blocking method to separate the ions' contribution from the total conductivity. Taken $\mathrm{Cu}_{2} \mathrm{~S}$ as an example, two ionic $\mathrm{Cu} / \mathrm{CuBr}$ electrodes are used to connect with the two ends of the bar-shape $\mathrm{Cu}_{2} \mathrm{~S}$ sample to consist a $\mathrm{Cu}|\mathrm{CuBr}| \mathrm{Cu}_{2} \mathrm{~S}|\mathrm{CuBr}| \mathrm{Cu}$ galvanic cell. These ionic electrodes can block the electrons passing across the $\mathrm{Cu}_{2} \mathrm{~S} \mid \mathrm{CuBr}$ interfaces while allowing the ions to freely migrate through them. Meanwhile, two ionic $\mathrm{Cu} / \mathrm{CuBr}$ probes are used to record the potential variation on the sample generated by the movable ions. Using this method, the $\sigma_{i}$ values of $\mathrm{Cu}_{2} \mathrm{~S}^{[26,28-29]}, \mathrm{Cu}_{2} \mathrm{Se}^{[30]}, \mathrm{Ag}_{2} \mathrm{~S}^{[31]}$, $\mathrm{Ag}_{2} \mathrm{Se}^{[32]}, \mathrm{Ag}_{2} \mathrm{Te}^{[32]}$ and $\mathrm{Li}_{\delta} \mathrm{Cu}_{2-\delta} \mathrm{S}(\delta=0 \sim 0.25)^{[33]}$ have been successfully measured. However, this elec-

Received date: 2017-03-20; Modified date: 2017-05-10

Foundation item: National Science Fund for Distinguished Young Scholars (51625205); National Natural Science Foundation of China $(51402337,51472262)$

Biography: LIU Yong-Ying (1992-), female, candidate of Master degree. E-mail: drymar@student.sic.ac.cn

Corresponding author: SHI Xun, professor. E-mail: xshi@mail.sic.ac.cn 
tron-blocking method is limited in very narrow temperature range because it requires very special materials as the ionic electrodes and probes which can only conduct ions. For example, if we choose $\mathrm{CuBr}$ to make the galvanic cell, this method can be only used at $385 \sim 469^{\circ} \mathrm{C}^{[34]}$. Otherwise, $\mathrm{CuBr}$ is not a unipolar ionic-conductor and this electron-blocking method does not work.

Besides using the ionic electrodes to block electrons, the electrons' contribution $\left(\sigma_{\mathrm{e}}\right)$ can be also extracted from the total conductivity by using the pure electric electrodes $(e . g . \mathrm{Ni}, \mathrm{Pt})$ to block ions. In this case, the ions are not allowed to pass across the interfaces and their motions are limited inside the measured sample. If there is no ion-precipitation, the ion numbers in the materials are not changed. After a long time at high temperature, the sample will finally reach a steady state, in which only electrons directionally pass across the sample. Via recording the curves of the establishment and decay of the ion concentration polarization, the $\sigma_{i}$ values can be measured according to the Yokota's model ${ }^{[26]}$. If this ion-blocking method works, it is possible to measure the $\sigma_{i}$ values in liquid-like TE materials at any temperature ranges. Especially, as compared with the electronblocking method, this ion-blocking method does not require any special ionic electrodes and probes to consist the galvanic cell, thus the measurement should be more simple and convenient. However, since this method was proposed by Yokota in $1953^{[26]}$, its utilization has been scarcely reported in the published literatures. The details about the measurement instrument and the possible influencing factors on the measurement accuracy are still unclear so far.

In this study, a home-made instrument has been built based on the ion-blocking method to measure the ionic conductivity in liquid-like TE materials. The basic construction of the instrument, the measurement principle, and the possible related factors are introduced. The measured $\sigma_{i}$ values for $\mathrm{Cu}_{1.99} \mathrm{~S}$ and $\mathrm{Cu}_{7} \mathrm{PSe}_{6}$ are also presented to show the validity of this study.

\section{Instrument developed for ionic conductivity measurement}

\subsection{Basic construction of the instrument}

The home-made instrument designed to measure $\sigma_{i}$ consists of three parts, termed as the temperature/atmosphere-controlling unit, electric-controlling unit, and data-acquiring unit. The sketch map of this home-made instrument is shown in Fig. 1. The commercial thermal expansion equipment (Netzsch $402 \mathrm{C}$, Germany) is taken as the temperature/atmosphere-controlling unit, which can provide high-precision temperature control $\left( \pm 0.01{ }^{\circ} \mathrm{C}\right)$ from room temperature to $1600^{\circ} \mathrm{C}$ in vacuum or inert atmosphere. The electric-controlling unit is realized by the Agilent B2901A, which connects with two nickel blocks $\left(\Phi 10 \times 10 \mathrm{~mm}^{3}\right)$. The Agilent B2901A as power supplier can provide a constant DC current ranging from $1 \mathrm{pA}$ to $10 \mathrm{~A}$. The data-acquiring unit is realized by the Agilent 32970A, which connects with two R-type thermocouples pasted on the measured sample to real-time monitor and record the temperature and voltage signals. The measured sample is tightly fixed between the nickel blocks by using the length adjustable $\mathrm{Al}_{2} \mathrm{O}_{3}$ rod in the Netzsch $402 \mathrm{C}$ instrument. These two nickel blocks also act as the ion-blocking electrodes to block the ions migrating out from the measured sample. The nickel electrodes, sample, and thermocouples are packaged into the furnace chamber of the Netzsch DIL 402C equipment.

\subsection{Measurement principles and steps}

All the measurements are carried out in high purity Argon atmosphere. The dimension of the measured sample is $1.5 \mathrm{~mm} \times 1.5 \mathrm{~mm} \times 10 \mathrm{~mm}$. After the temperature of the furnace chamber is raised to the specified value, the Agilent B2901A is switched on. A constant DC current flows from one nickel electrode to the measured sample and then flows out from the other nickel electrode. Fig. 2(a) shows the sketch map of the ion motion in the measured sample when a current is switched on and off. At the instant when the current is stressed on the sample, the initial random ion migration (step 1) is orientated along the current direction (step 2). At this instant, the
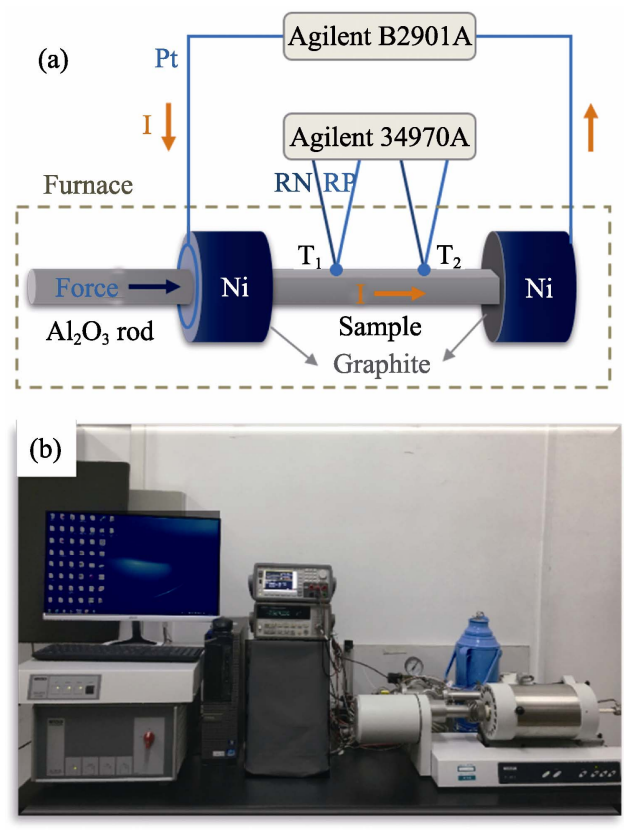

Fig. 1 Sketch map (a) and optical image (b) for the homemade instrument built for the ionic conductivity measurement. 
potential variation on the sample is caused by both the electron motion and ion migration. Then, the potential drop on the sample (named as the initial voltage) is defined as

$$
V_{i}=\frac{j d}{\sigma_{i}+\sigma_{e}},
$$

where $j$ is the current density, $d$ is the distance between the two R-type thermocouples pasted on the sample. The interfaces between sample and nickel electrodes allow the free movements for electrons, but not for ions. Thus, the ions migrated from the high potential place will accumulate at the low potential place, forming an ion concentration gradient along the sample. This ion concentration gradient will further induce the ion back-diffusion from the low potential place to the high potential place and counter-balance the ion-migration. If there is no ionprecipitation, the sample will finally reach a dynamic equilibrium state (step 3), in which only the current of electrons flows through the sample. At this time, the potential drop on the sample (named as the stationary voltage) is defined as

$$
V_{s}=\frac{j d}{\sigma_{e}} .
$$

If the current is switched off at this dynamic equilibrium state, the electron motion will immediately disappear while the ions at the high concentration place will gradually diffuse back to the low concentration place (step 4). Finally, the ions distribution in the sample will return to the initial homogeneous state (step 1).

The potential variation for such processes mentioned above is shown in Fig. 2(b). It has two parts. One is for turning on the current (called process 1) and another is for tuning off the current (called process 2). These two processes are reversible in an ideal case. We thus use the symbol ' 1 ' for process 1 and ' 2 ' for process 2 (see Fig. 2(c)). The voltage difference between $V_{i}$ and $V_{\mathrm{s}}$ is defined as the residual voltage $V_{\mathrm{r}}$

$$
V_{r}=V_{s}-V_{i}=\frac{\sigma_{i}}{\sigma_{i}+\sigma_{e}} \cdot \frac{j d}{\sigma_{e}} .
$$

Measuring the initial voltage $V_{i}$, the stationary voltage $V_{s}$, and the residual voltage $V_{r}$ gives the ionic conductivity at specified temperature

$$
\sigma_{i}=\frac{j d}{V_{i}} \cdot \frac{V_{r}}{V_{s}} .
$$

Therefore, we can calculate the $\sigma_{i}$ by using the data of process $1\left(\sigma_{i 1}\right)$ and process $2\left(\sigma_{i 2}\right)$. Yokota used the $V_{i 1}$, $V_{s 1}$, and $V_{\mathrm{r} 2}$ to calculate the $\sigma_{i}\left(\sigma_{i \mathrm{Y}}\right)$ for somewhat unknown reason. As we mentioned, in an ideal case, $\sigma_{i 1}$ should be the same as $\sigma_{i 2}$. However, taking into account the measurement errors, the average value $\left(\sigma_{i \mathrm{~A}}\right)$ of
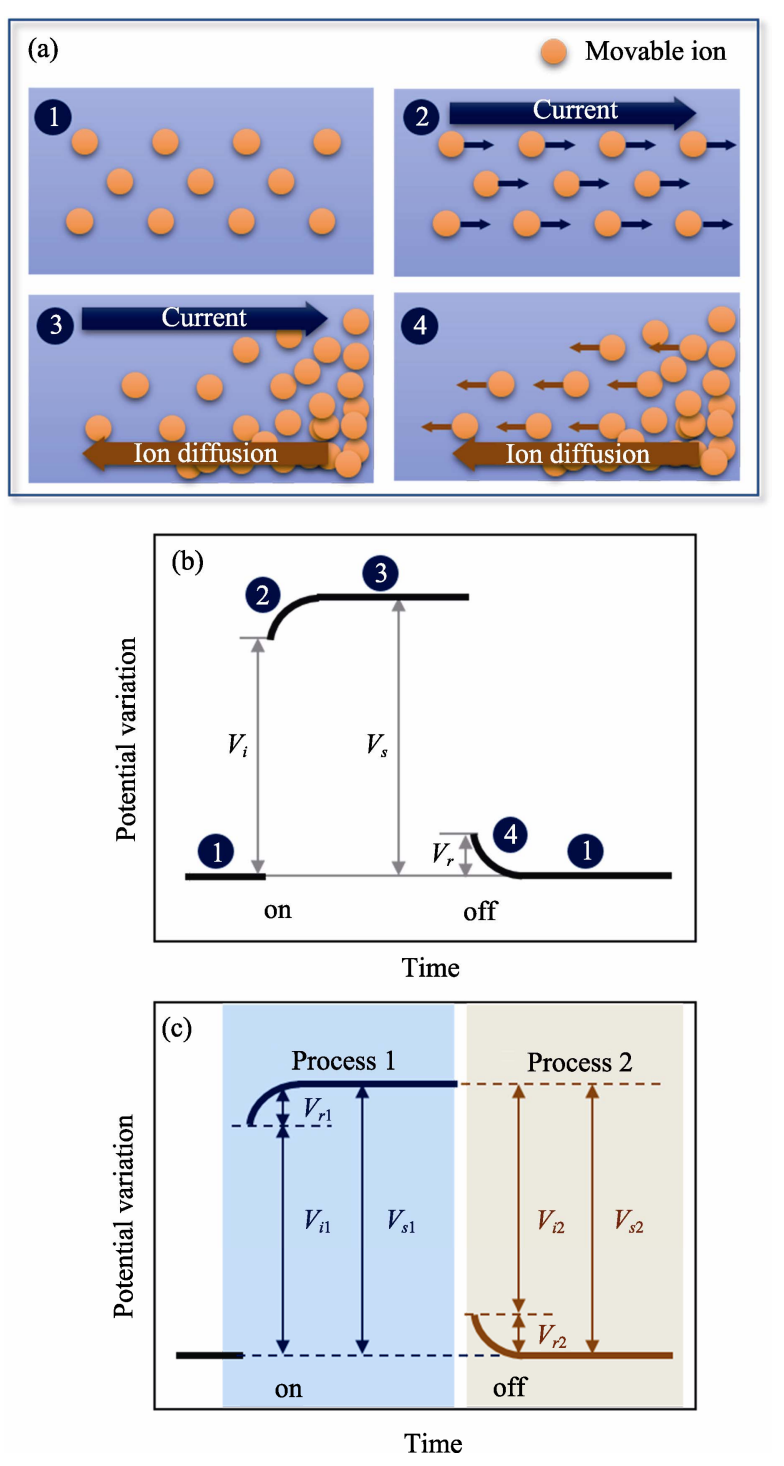

Fig. 2 (a) Sketch map of the ion motion process when a current is switched on and off. (b) A typical potential variation curve on a sample caused by the ion motion. (c) Process 1 is for current on and process 2 is for current off

process 1 and process 2 is recommended. Thus the $\sigma_{i}$ is

$$
\sigma_{i A}=\frac{2 j d}{V_{i 1}+V_{i 2}} \cdot \frac{V_{r 1}+V_{r 2}}{V_{s 1}+V_{s 2}} .
$$

The ionic conductivities discussed below are calculated by Eq. (5).

\section{Results and discussions}

\subsection{Related factors and measurement im- provements}

Based on Eq. (1)-(5), this ion-blocking method seems very simple and the ionic conductivity can be easily measured. However, in the real test, many factors might influence the measurement accuracy. Especially, for most liquid-like TE materials, the ionic conductivity usually weighs a small proportion in the total conductivity, thus 
these factors might introduce quite large uncertainties or even wrong results. Here, the main factors are discussed. Then the possible strategies to increase the measurement accuracy are also proposed.

\subsubsection{Peltier effect and Seebeck effect}

The ion-blocking method requires a current flowing through the sample to induce the ion concentration polarization. However, the current will simultaneously generate Peltier effect to conduct heat from the sample's one end to the other end, thereby leading to a temperature gradient along the sample. This temperature gradient will generate a Seebeck voltage on the sample, which contributes to the measured voltage. To better clarify this issue, we chose a filled $\mathrm{CoSb}_{3}$ sample which does not include any movable ions as an example to show the role of Peltier effect and Seebeck effect. Two thin platinum wires $(\Phi 0.1 \mathrm{~mm})$ connecting with the DC power supply (Agilent B2901A) are pasted on the two ends of sample to conduct electrons but minimize the heat exchange between the filled $\mathrm{CoSb}_{3}$ sample and environment (see the inset in Fig. 3(a)). In this thermal-insulating condition, the heat conduction along the current direction caused by the Peltier effect will induce obvious temperature variation on the filled $\mathrm{CoSb}_{3}$ sample to generate extra potential variation as shown in Fig. 3(a). These curves are quite similar to that shown in Fig. 2(b). However, there are no movable ions in filled $\mathrm{CoSb}_{3}$ sample and the ionic conductivity is zero. According to the principle of Harman's method ${ }^{[35]}$, such kind of potential variation is caused by the Peltier effect and Seebeck ef- fect. These effects will definitely influence the measurement accuracy and overestimate the ionic conductivity.

In order and suppress the Peltier effect and Seebeck effect, the influence of samples should be designed to easily exchange heat with the environment to minimize the temperature variation on the sample. In this study, two large and high thermal-conductive nickel blocks $\left(\Phi 10 \times 10 \mathrm{~mm}^{3}\right)$ are adhered on the two ends of the sample to accelerate the heat exchange between the sample and environment (see the inset in Fig. 3(b)). Here, we still take the filled $\mathrm{CoSb}_{3}$ sample as an example to demonstrate the role of these nickel blocks. As shown in Fig. 3(b), comparing to the nearly thermal- insulating condition, when the current is switched on and off, the potential and temperature variations are greatly weakened because the heat accumulated at the end of the sample can be rapidly absorbed by the nearby nickel blocks. Under the current density of $0.3 \mathrm{~A} / \mathrm{cm}^{2}$, the $V_{\mathrm{S}} / V_{i}$ ratio in the thermal-conducting condition is almost close to 1 , as compared with the value of 1.28 in the thermal- insulating condition.

The above strategy can effectively suppress the influence of Peltier effect and Seebeck effect on the ionic conductivity measurement. Here, we use a $\mathrm{Cu}_{1.94} \mathrm{~S}$ sample to show how to improve the ionic conductivity measurement. At $477^{\circ} \mathrm{C}$, the measured $\sigma_{i}$ in the thermal-insulating condition is $1540 \mathrm{~S} / \mathrm{m}$. This $\sigma_{i}$ value is definitely overestimated due to the presence of obvious temperature gradient $\left(0.4^{\circ} \mathrm{C} / \mathrm{mm}\right.$, see Fig. $4(\mathrm{~b})$ red curve)
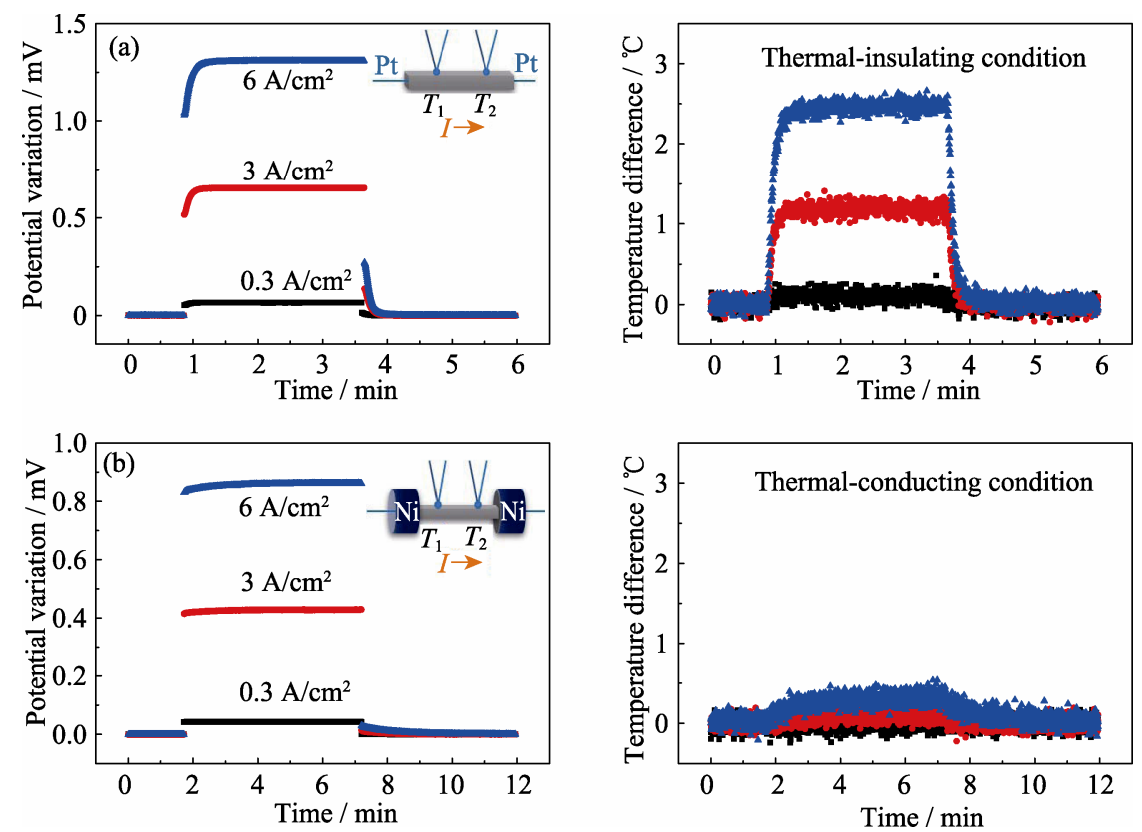

Fig. 3 Variations of potential and temperature difference on a filled $\mathrm{CoSb}_{3}$ sample at $227^{\circ} \mathrm{C}$ in (a) nearly thermal-insulating condition and (b) thermal-conducting condition under different current densities. Both the potential and temperature difference are measured between the two R-Type thermocouples pasted on the sample 

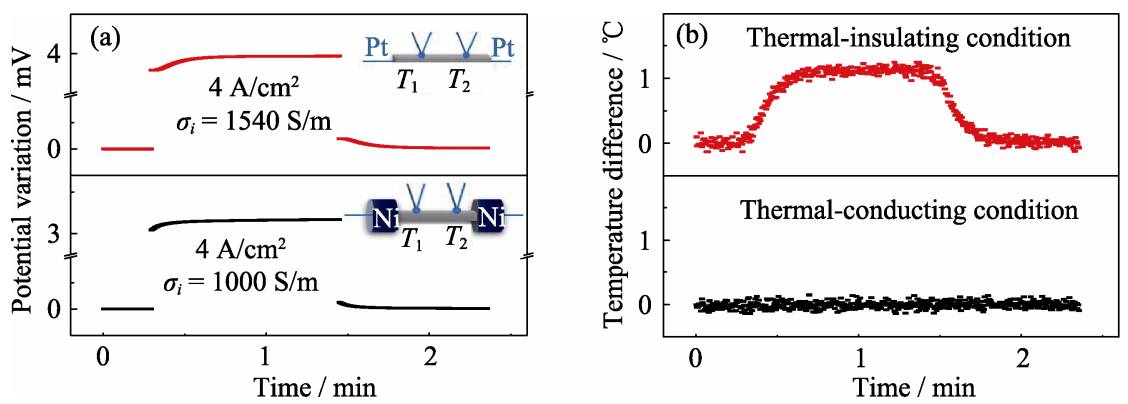

Fig. 4 Variations of potential (a) and temperature difference (b) on a $\mathrm{Cu}_{1.94} \mathrm{~S}$ sample at $477^{\circ} \mathrm{C}$ in thermal-insulating condition and thermal-conducting condition

along the $\mathrm{Cu}_{1.94} \mathrm{~S}$ sample. Via adhering two large $\mathrm{Ni}$ blocks on the two samples' ends to eliminate the temperature gradient (see Fig. 4(b) black curve), the measured $\sigma_{i}$ in this thermal-conducting condition is only $1000 \mathrm{~S} / \mathrm{m}$, about $35 \%$ lower than that in the thermalinsulating condition.

\subsubsection{Ion-precipitation}

The ion-blocking method requires no ions to precipitate out from the measured sample during the whole measurement process. However, if the stressed current is over-high, ions will precipitate from the sample to change material's chemical composition and electrical conductivity. This is also a common factor influencing the measurement accuracy. Taken copper sulfide $\mathrm{Cu}_{1.99} \mathrm{~S}$ as an example, Fig. 5(a) shows the potential variation curves at $477^{\circ} \mathrm{C}$ under different test current densities. When the test current densities are less than $0.048 \mathrm{~A} / \mathrm{cm}^{2}$,
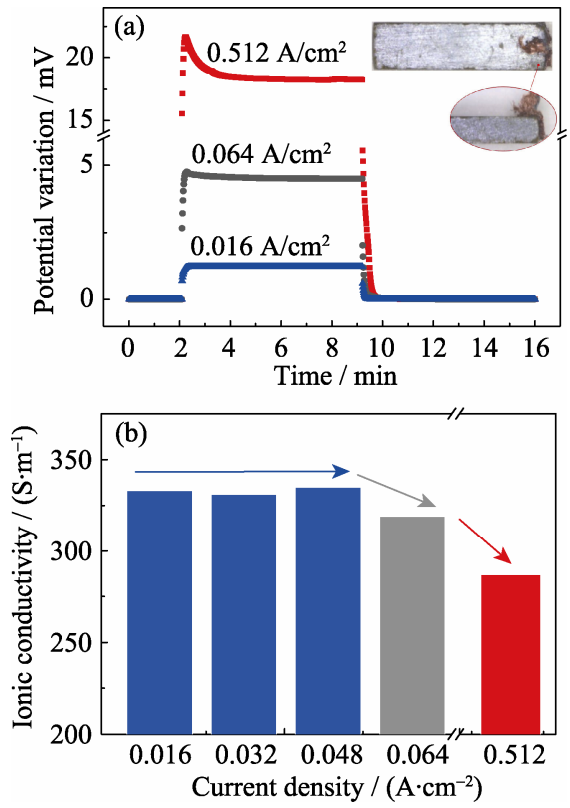

Fig. 5 (a) Potential variation curves for $\mathrm{Cu}_{1.99} \mathrm{~S}$ under different test current densities at $477^{\circ} \mathrm{C}$. (b) $\sigma_{i}$ values calculated based on the potential variation curves shown in (a)

The inset in (a) shows the optical image of the sample after the measurement under $0.512 \mathrm{~A} / \mathrm{cm}^{2}$. Obvious Cu precipitation is observed on the sample's surface the curves are similar with the standard curve shown in Fig. 2. The $\sigma_{i}$ values obtained from these curves are around $330 \mathrm{~S} / \mathrm{m}$ (see Fig. 5(b)). No $\mathrm{Cu}$ precipitation is observed after the measurements. However, when the test current density is increased to $0.064 \mathrm{~A} / \mathrm{cm}^{2}$, the voltage firstly increases to reach a maximum value and then slightly decreases with further prolonging the current stress duration. Using the $V_{i}, V_{\mathrm{s}}$, and $V_{\mathrm{r}}$ values extracted from this curve, the calculated $\sigma_{i}$ value is $320 \mathrm{~S} / \mathrm{m}$. When the current density is further increased to $0.512 \mathrm{~A} / \mathrm{cm}^{2}$, the voltage drop from the maximum value is more obvious and the calculated $\sigma_{i}$ value is only $280 \mathrm{~S} / \mathrm{m}$. After the measurement, we found obvious copper metallic precipitates on the sample's surface (see the inset in Fig. 5(a)). Hence, the test current should be as small as possible to ensure the high measurement accuracy.

\subsubsection{Positions of the thermocouples}

The key point of the present ion-blocking method lies on whether the $V_{i}, V_{\mathrm{s}}$, and $V_{\mathrm{r}}$ values shown in Fig. 2(b) can be accurately measured. For a fixed sample, these voltages are simultaneously determined by the magnitude of the test current density $j$ and the distance $d$ between these two R-type thermocouples. As we discussed above, the test current density should be as tiny as possible to suppress the Peltier effect and Seebeck effect. However, too small test current density generates too small potential variation with very weak signal/noise ratio, which will influence the ion conductivity measurement accuracy especially for those samples with low electrical resistivity. Under the same current density, increasing the distance between the two R-type thermocouples can obtain larger voltage values and enhance the signal/noise ratio. In addition, increasing the distance between the two R-type thermocouples can also ensure the low measurement error when measuring the $d$ value.

However, the positions of the thermocouples should not be too close to the samples' two ends. In the real test, the two end-surfaces of the measured sample are difficult to completely contact with the nickel blocks. The actual contact area in the ends is much smaller than the cross- 
sectional area of the sample. Thus, the real current density nearby the ends of the sample might be larger than the nominal value, leading to the underestimation of the $\sigma_{i}$ value by Eq. 5 . As shown in Fig. 6, for the same $\mathrm{Cu}_{1.99} \mathrm{~S}$ sample, when $d$ is increased to $6 \mathrm{~mm}$, the potential curve has large signal/noise ratio. The calculated $\sigma_{i}$ value from this curve is $103 \mathrm{~S} / \mathrm{m}$. However, for the same $\mathrm{Cu}_{1.99} \mathrm{~S}$ sample, when $d$ is increased to $9.5 \mathrm{~mm}$, the calculated $\sigma_{i}$ value is $75 \mathrm{~S} / \mathrm{m}$, which is about $30 \%$ lower than that at $d=6 \mathrm{~mm}$. Thus, the $d$ value should be carefully chosen for each measured sample according to its electrical resistivity and geometric length.

\subsubsection{Oxidation and volatilization}

Although the measurement is carried out under vacuum or inert atmosphere, slightly oxidation might still happen due to the high test temperature. Furthermore, since almost all liquid-like TE materials consist of volatile elements such as $\mathrm{S}, \mathrm{Se}, \mathrm{Te}$, and $\mathrm{Sb}$, the volatilization of these elements at high temperature during the measurement is inevitable if the samples are not properly protected. Both oxidation and volatilization will change the chemical compositions of the sample and the measured results. Here, we take a $\mathrm{Cu}_{7} \mathrm{PSe}_{6}$ sample as an example. As shown in Fig. 7 , at $277^{\circ} \mathrm{C}$, if the sample is not protected, the electrical resistance of the $\mathrm{Cu}_{7} \mathrm{PSe}_{6}$ sample is significantly increased with the value $20 \%$ than the initial number after $120 \mathrm{~min}$. Such electrical resistance variation will definitely influence the ionic conductivity measurement accuracy.

In order to prevent the oxidation and volatilization, we used one kind of heat resistant silicone sealant to coat on the sample. The optical picture of one coated $\mathrm{Cu}_{7} \mathrm{PSe}_{6}$ sample is shown in the inset of Fig. 7. This coating can prevent the sample's surfaces to directly contact with the atmosphere. Thus, the oxidation and volatilization should be effectively suppressed by this method. As we have expected, after $120 \mathrm{~min}$ at $277^{\circ} \mathrm{C}$ the resistance is almost

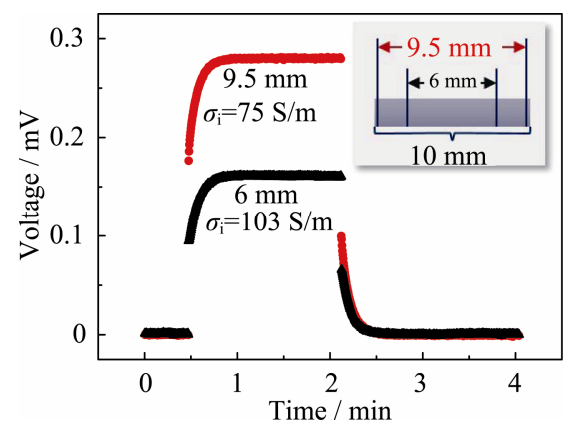

Fig. 6 Potential variation curves for $\mathrm{Cu}_{1.99} \mathrm{~S}$ measured under different distances between the two R-type thermocouples at $227^{\circ} \mathrm{C}$

The test current density is $0.04 \mathrm{~A} / \mathrm{cm}^{2}$

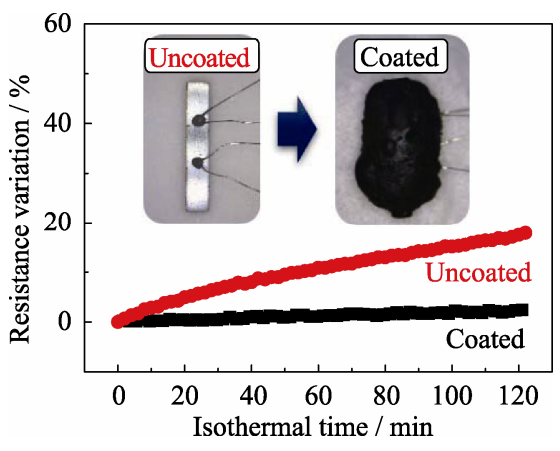

Fig. 7 Resistance variations of uncoated and coated $\mathrm{Cu}_{7} \mathrm{PSe}_{6}$ samples at $277^{\circ} \mathrm{C}$

The inset shows the optical images of these two samples

unchanged. In this way, the influence of oxidation and volatilization can be greatly weakened in the ionic conductivity measurement.

\subsection{Measured $\sigma_{i}$ values for typical liquid-like TE materials}

Using this home-made instrument, we successfully measured the ionic conductivities of $\mathrm{Cu}_{1.99} \mathrm{~S}$ and $\mathrm{Cu}_{7} \mathrm{PSe}_{6}$. The data are listed in Table 1. Clearly, the $\sigma_{i}$ values calculated by four kinds of methods are very close with a deviation less than $6 \%$, indicating these methods are very reliable and the measurement accuracy is about $6 \%$.

Since the present ion-blocking method does not rely on the special ionic electrodes, the $\sigma_{i}$ values in a quite broad temperature range can be successfully obtained. For example, for the copper sulfides $\mathrm{Cu}_{2-\delta} \mathrm{S}$, the previous literatures only reported the $\sigma_{i}$ values of the hexagonal phase. Nevertheless, the $\sigma_{i}$ values of the cubic phase

Table 1 Ionic conductivities for $\mathrm{Cu}_{1.99} \mathrm{~S}$ and $\mathrm{Cu}_{7} \mathrm{PSe}_{6}$ calculated by using the Yokota's method $\left(\sigma_{i \mathrm{Y}}\right)$, the data of process $1\left(\sigma_{i 1}\right)$ and process $2\left(\sigma_{i 2}\right)$, and the average data of process 1 and process $2\left(\sigma_{\mathrm{iA}}\right)$

\begin{tabular}{cccccc}
\hline Sample & $T /{ }^{\circ} \mathrm{C}$ & $\begin{array}{c}\sigma_{i Y} / \\
\left(\mathrm{S} \cdot \mathrm{m}^{-1}\right)\end{array}$ & $\begin{array}{c}\sigma_{i 1} / \\
\left(\mathrm{S} \cdot \mathrm{m}^{-1}\right)\end{array}$ & $\begin{array}{c}\sigma_{i 2} / \\
\left(\mathrm{S} \cdot \mathrm{m}^{-1}\right)\end{array}$ & $\begin{array}{c}\sigma_{i A} / \\
\left(\mathrm{S} \cdot \mathrm{m}^{-1}\right)\end{array}$ \\
\hline \multirow{6}{*}{$\mathrm{Cu}_{1.99} \mathrm{~S}$} & 177 & 58 & 57 & 58 & 58 \\
& 227 & 97 & 98 & 96 & 97 \\
& 277 & 137 & 137 & 138 & 137 \\
& 427 & 178 & 179 & 175 & 177 \\
& 452 & 309 & 305 & 314 & 309 \\
& 477 & 327 & 326 & 328 & 327 \\
& 502 & 349 & 351 & 347 & 349 \\
-------------127 & 369 & 356 & 376 & 366 \\
& 527 & 50 & 55 & 50 & 53 \\
$\mathrm{Cu}_{7} \mathrm{PSe}_{6}$ & 177 & 79 & 81 & 79 & 80 \\
& 227 & 118 & 117 & 118 & 118 \\
& 277 & 163 & 172 & 163 & 167 \\
\hline
\end{tabular}


(above around $427^{\circ} \mathrm{C}$ ) is absent because the temperature limitation for the $\mathrm{CuBr}$ ionic electrode mentioned above. Using the present ion-blocking method, the $\sigma_{i}$ values of $\mathrm{Cu}_{1.99} \mathrm{~S}$ from $177^{\circ} \mathrm{C}$ to $527^{\circ} \mathrm{C}$ have been measured. As shown in Fig. 8(a), the $\sigma_{i}$ values of these liquid-like TE materials are between $50 \mathrm{~S} / \mathrm{m}$ and $500 \mathrm{~S} / \mathrm{m}$, which are very high values as compared with those of the metal halogens (e.g. $\mathrm{CuBr}^{[34]}$ and $\mathrm{Cu}_{3} \mathrm{CdI}_{5}{ }^{[36]}$ ).

The measured $\sigma_{i}$ values provide many useful information to help us to better understand these liquid-like TE materials. Based on the temperature dependence of the $\sigma_{i}$ values, we can calculate the ionic activation energy $\left(E_{\mathrm{a}}\right)$ by the equation

$$
\sigma_{i}=\sigma_{i 0} \exp \left(-E_{a} / k_{B} T\right),
$$

where $\sigma_{i 0}$ is a pre-exponential factor and $k_{\mathrm{B}}$ is the Boltzmann constant. As shown in Fig. 8(b), the $E_{\mathrm{a}}$ values for both $\mathrm{Cu}_{1.99} \mathrm{~S}$ and $\mathrm{Cu}_{7} \mathrm{PSe}_{6}$ are 0.1-0.2 eV, comparable with the $k_{\mathrm{B}} T$ at elevated temperature. In addition, $E_{\mathrm{a}}$ for $\beta-\mathrm{Cu}_{1.99} \mathrm{~S}$ is larger than that of the $\alpha-\mathrm{Cu}_{1.99} \mathrm{~S}$ phase. In $\beta-\mathrm{Cu}_{1.99} \mathrm{~S}$, most copper atoms are located in the sulfur layers with the $\mathrm{Cu}-\mathrm{S}$ bond length of $\sim 0.22 \mathrm{~nm}$. However, in $\alpha-\mathrm{Cu}_{1.99} \mathrm{~S}$, most copper atoms are located inside the tetrahedral anti-fluorite positions with the $\mathrm{Cu}-\mathrm{S}$ bond length of $\sim 0.24 \mathrm{~nm}$. The shorter $\mathrm{Cu}-\mathrm{S}$ bond length in the $\beta-\mathrm{Cu}_{1.99} \mathrm{~S}$ phase suggests that the $\mathrm{Cu}-\mathrm{S}$ chemical bonds wherein are stronger than those in the $\alpha-\mathrm{Cu}_{1.99} \mathrm{~S}$ phase. Thus, a larger energy is required for the $\mathrm{Cu}$ ions in the $\beta-\mathrm{Cu}_{1.99} \mathrm{~S}$ phase to hop from one site to another.

Furthermore, based on the measured $\sigma_{i}$ values, we can
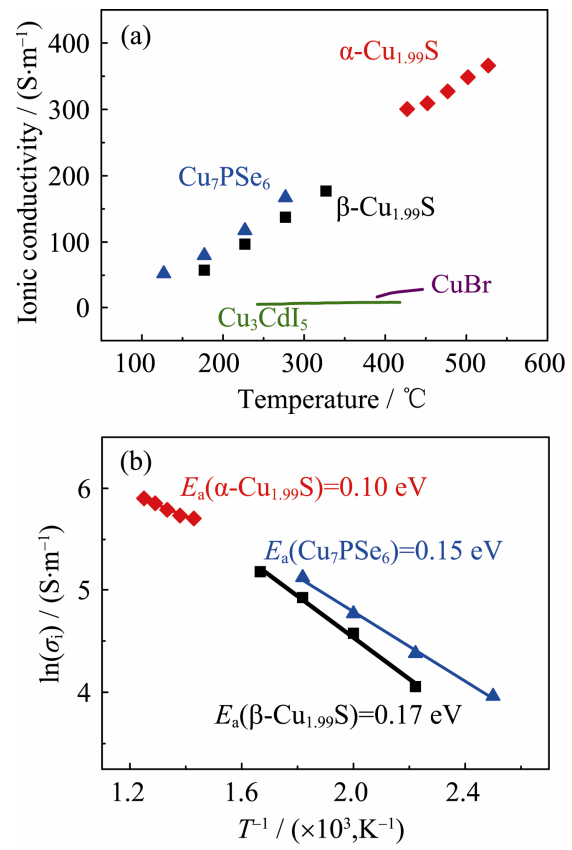

Fig. 8 (a) Ionic conductivity $\left(\sigma_{i}\right)$ and (b) ionic activation energy $\left(E_{\mathrm{a}}\right)$ for liquid-like TE materials

Ionic conductivities are calculated by Eq. (5) also calculate the ionic self-diffusion coefficient $\left(D_{i}\right)$ by the equation (7) and (8):

$$
\begin{aligned}
\mu_{i} & =\sigma_{i} / n_{i} e, \\
D_{i} & =\mu_{i} k_{B} T / e,
\end{aligned}
$$

where $n_{i}$ is the mobile $\mathrm{Cu}$ ions concentration and $\sigma_{i}$ is the ionic mobility. By assuming that the $\mathrm{Cu}$ ions in a liquidlike material are fully ionized and all $\mathrm{Cu}$ ions take part in the ionic conductivity, $n_{i}$ can be simply regarded as a constant value at different temperatures which equals to the total $\mathrm{Cu}$ ions concentration in this material. For example, $n_{i}$ for $\mathrm{Cu}_{1.99} \mathrm{~S}$ is $4.62 \times 10^{22} \mathrm{~cm}^{-3}$. At $227^{\circ} \mathrm{C}$, the calculated $D_{i}$ is $5.63 \times 10^{-6} \mathrm{~cm}^{2} / \mathrm{s}$. This $D_{i}$ value is comparable with those in typical simple liquid self-diffusion systems, e.g. $1.6 \times 10^{-5} \mathrm{~cm}^{2} / \mathrm{s}$ in Argon and $2.2 \times 10^{-5}$ $\mathrm{cm}^{2} / \mathrm{s}$ in water ${ }^{[37]}$. This can well account for the $\mathrm{Cu}$ ions' liquid-like behavior in the rigid sulfur framework.

\section{Conclusion}

In this study, based on the principle of ion-blocking method proposed by Yokota, we built a home-made instrument to measure the ionic conductivity in liquid-like TE materials. The basic construction of the instrument and the measurement principle are introduced. The influences of Peltier effect/Seebeck effect, ion precipitation, positions of the thermocouples, and oxidation and volatilization on the measurement accuracy are also demonstrated and discussed. Then, several strategies were proposed to increase the measurement accuracy. Using this instrument, the $\sigma_{i}$ values of $\mathrm{Cu}_{1.99} \mathrm{~S}$ and $\mathrm{Cu}_{7} \mathrm{PSe}_{6}$ were successfully measured.

\section{References:}

[1] CHEN L D, XIONG Z, BAI S Q. Recent progress of thermoelectric nano-composites. Journal of Inorganic Materials, 2010, 25(6): 561-568.

[2] ZHU T, HU L, ZHAO X, et al. New insights into intrinsic point defects in $\mathrm{V}_{2} \mathrm{VI}_{3}$ thermoelectric materials. Advanced Science, 2016, 3(7): 1600004

[3] SHI X, CHEN L, UHER C. Recent advances in high-performance bulk thermoelectric materials. International Materials Reviews, 2016, 61(6): 379-415.

[4] ZHAN B, LAN J L, LIU Y C, et al. Research progress of oxides thermoelectric materials. Journal of Inorganic Materials, 2014, 29(3): 237-244.

[5] SU X, WEI P, LI H, et al. Multi-scale microstructural thermoelectric materials: transport behavior, non-equilibrium preparation, and applications. Advanced Materials, 2017, 29(20): 160213

[6] LIU H, SHI X, XU F, et al. Copper ion liquid-like thermoelectrics. Nature Materials, 2012, 11(5): 422-425.

[7] HE Y, DAY T, ZHANG T, et al. High thermoelectric performance in non-toxic earth-abundant copper sulfide. Advanced Materials, 2014, 26(23): 3974-3978.

[8] HE Y, LU P, SHI X, et al. Ultrahigh thermoelectric performance in mosaic crystals. Advanced Materials, 2015, 27(24): 3639-3644. 
[9] HE Y, ZHANG T, SHI X, et al. High thermoelectric performance in copper telluride. $N P G$ Asia Materials, 2015, 7(8): e210.

[10] QIU P F, WANG X B, ZHANG T S, et al. Thermoelectric properties of Te-doped ternary CuAgSe compounds. Journal of Materials Chemistry A, 2015, 3(44): 22454-22461.

[11] HONG A J, LI L, ZHU H X, et al. Anomalous transport and thermoelectric performances of $\mathrm{CuAgSe}$ compounds. Solid State Ionics, 2014, 261: 21-25.

[12] QIU P F, ZHANG T S, QIU Y T, et al. Sulfide bornite thermoelectric material: a natural mineral with ultralow thermal conductivity. Energy Environmental Science, 2014, 7(12): 4000-4006.

[13] BHATTACHARYA S, BASU R, BHATT R, et al. $\mathrm{CuCrSe}_{2}$ : a high performance phonon glass and electron crystal thermoelectric material. Journal of Materials Chemistry A, 2013, 1(37): 1128911294.

[14] PEDERSEN B L, Birkedal H, NYGREN M, et al. The effect on $\mathrm{Mg}$ doping on the thermelectric performance of $\mathrm{Zn}_{4} \mathrm{Sb}_{3}$. Journal of Applied Physics, 2009, 105: 013517.

[15] WELDERT K S, ZEIER W G, DAY T W, et al. Thermoelectric transport in $\mathrm{Cu}_{7} \mathrm{PSe}_{6}$ with high copper ionic mobility. Journal of the American Chemical Society, 2014, 136(34): 12035-12040.

[16] JIANG B B, QIU P F, EIKELAND E, et al. $\mathrm{Cu}_{8} \mathrm{GeSe}_{6}$-based thermoelectric materials with an argyrodite structure. Journal of Materials Chemistry C, 2017, 5: 943-952.

[17] SHI X, CHEN L. Thermoelectric materials step up. Nature Materials, 2016, 15(7): 691-692.

[18] HUANG X Y, XU Z, CHEN L D. New thermoelectric materials with half-heusler structure. Journal of Inorganic Materials, 2004, 19(1): $25-30$

[19] LI J, LIU W, ZHAO L. High-performance nanostructured thermoelectric materials. NPG Asia Materials, 2010, 2(4): 152-158.

[20] DENNLER G, CHMIELOWSKI R, JACOB S, et al. Are binary copper sulfides/selenides really new and promising thermoelectric materials. Advanced Energy Materials, 2014, 4(9): 1301581.

[21] QIU P F, SHI X, CHEN L D. Cu-based thermoelectric materials. Energy Storage Materials, 2016, 3: 85-97.

[22] BROWN D R, DAY T, CAILLAT T, et al. Chemical stability of $(\mathrm{Ag}, \mathrm{Cu})_{2} \mathrm{Se}$ : a historical overview. Journal of Electronic Materials, 2013, 42(7): 2014-2019.

[23] SATO H, KIKUCHI R. Cation diffusion and conductivity in solid electrolytes. I. The Journal of Chemical Physics, 1971, 55(2):
677-702.

[24] ZHANG S S, XU K, JOW T R. Electrochemical impedance study on the low temperature of Li-ion batteries. Electrochimica Acta, 2004, 49(7): 1057-1061.

[25] ZHANG S S, XU K, JOW T R. EIS study on the formation of solid electrolyte interface in Li-ion battery. Electrochimica Acta, 2006, 51(8): 1636-1640.

[26] YOKOTA I. On the electrical conductivity of cuprous sulfide: a diffusion theory. Journal of the Physical Society of Japan, 1953, 8(5): 595-602.

[27] YOKOTA I. On the theory of mixed conduction with special reference to the conduction in silver sulfide group semiconductors. Journal of the Physical Society of Japan, 1961, 16(11): 22132223.

[28] MIYATANI S. Point contact of Pt and $\gamma-\mathrm{Cu}_{2} \mathrm{~S}$. Journal of the Physical Society of Japan, 1956, 11(10): 1059-1063.

[29] OKAMOTO K, KAWAI S. Electrical conduction and phase transition of copper sulfides. Japanese Journal of Applied Physics, 1973, 12(8): $1130-1138$.

[30] ISHIKAWA T, MIYATANI S. Electronic and ionic conduction in $\mathrm{Cu}_{2-\delta} \mathrm{Se}, \mathrm{Cu}_{2-\delta} \mathrm{S}$ and $\mathrm{Cu}_{2-\delta}(\mathrm{Se}, \mathrm{S})$. Journal of the Physical Society of Japan, 1977, 42(1): 159-167.

[31] MIYATANI S. $\alpha-\mathrm{Ag}_{2} \mathrm{~S}$ as a mixed conductor. Journal of the Physical Society of Japan, 1968, 24(2): 328-336.

[32] MIYATANI S. Ionic conductivity in silver chalcogenides. Journal of the Physical Society of Japan, 1981, 50(10): 3415-3418.

[33] BALAPANOV M K, GAFUROV I G, MUKHAMED'YANOV U $\mathrm{K}$, et al. Ionic conductivity and chemical diffusion in superionic $\mathrm{Li}_{x} \mathrm{Cu}_{2-x} \mathrm{~S}(0 \leqslant x \leqslant 0.25)$. Physica Status Solidi B, 2004, 241(1): 114-119.

[34] WAGNER J B, WAGNER C. Electrical conductivity measurements on cuprous halides. The Journal of Chemical Physics, 1957, 26(6): $1597-1601$.

[35] HARMAN T C. Special techniques for measurement of thermoelectric properties. Journal of Applied Physics, 1958, 29(9): 13731374.

[36] WOJAKOWSKA A, KRZYZAK E. Electrical conductivity of $\mathrm{CuBr}$ in the temperature range $500-1050 \mathrm{~K}$. Solid State Ionics, 2005, 176(37/38): 2711-2716.

[37] WANG L W. High chalcocite $\mathrm{Cu}_{2} \mathrm{~S}$ : a solid-liquid hybrid phase. Physical Review Letters, 2012, 108(8): 085703.

\title{
基于离子阻挡法测量电子-离子混合导体中离子电导率的研究
}

\author{
刘勇英 ${ }^{1,2}$, 仇鹏飞 ${ }^{1}$, 陈弘毅 ${ }^{1,2}$, 陈 瑞 ${ }^{1,2}$, 史 迅 ${ }^{1}$, 陈立东 ${ }^{1}$
}

(1. 中国科学院 上海硅酸盐研究所, 高性能陶瓷和超微结构国家重点实验室, 上海 200050; 2. 中国科学院大学, 北京 100864)

摘 要: 近年来, 具有诸多新的物理性质和优良热电性能的类液态材料获得了研究人员的广泛关注。离子电导率对 理解这类热电材料中的离子迁移行为非常关键。但是, 由于类液态热电材料中的离子电导率在总电导率中的贡献很 小, 因此很难利用传统方法精确测量其离子电导率。本研究基于 Yokota 提出的离子阻挡法, 尝试利用自主搭建的 设备测量类液态热电材料的离子电导率。本文详细介绍了该设备的基本构造、测试原理以及测试步骤, 分析了帕尔 贴效应/塞贝克效应、离子析出、电压测试点的位置和氧化挥发等因素对测试准确性的影响, 并提出了相应的解决 方案，成功测量了几种具有代表性的类液态热电材料的离子电导率。

关 键 词: 热电材料; 离子电导率; 离子阻挡法; 离子激活能

中图分类号: TQ174 文献标识码: A 